\title{
The Other Side of Medicalization: Self-Medicalization and Self-Medication
}

\author{
Sylvie Fainzang \\ Anthropologist, senior researcher \\ Director of research in the INSERM \\ (National Institute of health and Medical Research in France), Cermes3 \\ sylvie.fainzang@orange.fr
}

(published in Culture, Medicine and Psychiatry, 2013, 37, 3, 488-504).

\begin{abstract}
The concept of medicalization has given rise to considerable discussion in the social sciences, focusing especially on the extension of medicine's jurisdiction and its hold over our bodies through the reduction of social phenomena to individual biological pathologies. However, the process leading to medical treatment may start when individuals engage in self-medication and thus practice 'self-medicalization'. But can we apply to this concept the same type of analysis as the first, and see merely the individual's replication of the social control mechanisms to which he/she usually falls victim? This article aims to demonstrate that the medicalization individuals practice on themselves takes on a completely different meaning to that practiced by the medical profession. Empirical data collected in France show that self-medicalization, which may involve treating a problem medically when doctors believe it to be of a non-medical nature, can be an attempt by individuals to furnish a social explanation for their somatic problems and experiences. In this article, I examine the social and political significance of this phenomenon.
\end{abstract}

Keywords: self-medication, medicalization, de-medicalization, self-medicalization, pathological, diagnosis, symptom.

\section{Introduction}

The concept of medicalization has been fruitful for those in the social sciences considering the increasingly important role that medicine plays in industrialized societies. While authors have adopted different approaches to this phenomenon, particularly with regard to its social and political significance, most see therein the stamp of medicine and its influence over our bodies (Aïach and Delanoë, 1998).

However, it is clear that the process which renders a bodily state liable to medical treatment may originate with individuals themselves -as when they practice self-medicationsince the resulting medicalization is of their own making. Under such conditions, is it possible to apply the same type of analysis to the concept of medicalization as when it results from action taken by medical authorities? And in this case, can we also speak of social control in the context of self-medication?

In this paper, I demonstrate that while self-medication often results from the reproduction and renewal of a previous medical opinion, it may also result from a personal decision to suggest a medical interpretation for a problem, and therefore to resort to medical treatment. Drawing on empirical situations in which individuals decide, on their own initiative, to medicalize a phenomenon, I examine the social and political significance that may underlie what I refer to as "self-medicalization". I show that medicalization does not always have the meaning ascribed to it in social science literature, and that when it is done in the context of self-medication, may indeed have the opposite meaning. 


\section{Medicalization in the social sciences}

The social sciences have shed considerable light on the phenomenon of the "medicalization" of social life, a concept first used to describe the process through which human conditions and problems or aspects of existence previously outside the realm of medicine are constructed, defined and treated as medical conditions and problems. As such, they are placed under the authority of the doctors and healthcare professionals, who diagnose and treat them. Medicalization thus designates the extension of medical jurisdiction into the social lives of individuals, and is perceived as the medical management of a phenomenon that might have been - or which previously was - managed differently, by religion or law, for example (Zola, 1972). As early as 1975, Conrad (1975) used the example of childhood hyperactivity to highlight the increasing medicalization of deviant behavior. In stressing the pervasive nature of "medical social control," his analysis made an important contribution to the sociology of health. Conrad $(1985,1992,2007)$ states that medicalization occurs when a problem is defined in medical terms, using medical language, when it is understood within a medical framework or when it is treated by a medical procedure. Medicalization, taken as an extension of medical authority in different areas of everyday life, is thus understood from the perspective of the social control it implies when behavior deemed to be deviant is transferred from the social to the medical arena. This process has also been cited as evidence of the domination of medicine (Illich, 1975) ${ }^{1}$.

However, it should be noted that social control by medicine had previously been mentioned by functionalist authors such as Hallowell (1941) and Ackerknecht (1946) in reference to traditional societies. Hallowell demonstrated that the interpretation of illness fulfills a role of social control in societies lacking the political and legal institutions specialized in dealing with conflict and ensuring that norms are respected. Following the direction taken by Hallowell, Ackerknecht (1946) in turn indicated the role of social control played by the conceptualization and treatment of illness in traditional societies in which, as he put it, magico-religious medicine provides, at lesser expense, the services supplied in our societies by the courts, police, schoolteachers, priests and soldiers.

The impact of medicalization on the lives of individuals has become a matter of sustained interest in the social sciences. Not only does the sociological and political significance of this concept lie in the fact that medicalization describes a process whereby non-medical problems are defined and treated as medical issues, i.e. in terms of illness and disorder, but this process occurs whether the problems have any biological basis or not. Medicalization is thus generally perceived as an act of intrusion into the lives of individuals, involving the provision of a medical response to their difficulties. There is considerable literature demonstrating the medicalization of behavior and of life in general (e.g. Cohen and Bouchard, 1995). This work also owes part of its analysis to the seminal thinking of Foucault (1965) on the hold that medical and governmental authorities have over individuals through the act of managing their bodies and their health (Lupton, 1997). The process of medicalization is sometimes achieved through recourse to techno-scientific innovations, which has earned it the qualification of "biomedicalization" by Clarke (2000), i.e. medicalization achieved through highly techno-

\footnotetext{
${ }^{1}$ Within the context of his critique of industrial societies, Illich seized upon this notion to underline what he felt to be the considerable harm done by the medical profession and medical procedures, be it on a clinical, social or existential level, through the very use of concepts of health and illness.
} 
scientific biomedical practices. With this concept, Clarke - whose work draws on Foucauldian theory - aims to account for the historical shift from "control over" bodies to "transformations of" bodies, as she formulates it (Clarke et al., 2003: 180), and show that one dimension of the process of biomedicalization, along with the transformation of bodies, is the production of new individual and collective identities.

Within this context, the social sciences have called attention to medicine's current tendency to adopt an exclusively drug-based approach to human phenomena, and to psychological suffering in particular, by virtue of aligning illness with a molecule designed to alleviate it (Gori and Del Volgo, 2005). Medicine, in this case psychiatry, responds to the commercial demands of the pharmaceutical industry and is thereby reduced to the prescription of psychotropic substances to limit "deviance" and other "behavioral disorders". The concept of medicalization is therefore also used to account for the specific role played by the pharmaceutical industry, through its incentives to treat, manage or resolve physical or social phenomena via the use of medicines. Medicalization is increasingly examined from the angle of the "disease mongering" practiced by a pharmaceutical industry keen to create new markets and to engage in the medical exploitation of events in everyday life. In this regard, Nichter (1989) uses "pharmaceuticalization" to refer to "the appropriation of human problems to medicines" (p. 272), echoed by various French-speaking authors with the concept of "médicamentalisation" (Desclaux and Levy, 2003). Meanwhile, Dumit and Greenslit (2006) mention the "pharmaceuticalization of culture" to account for the process by virtue of which pharmaceutical language contributes towards the building of modern identity.

To a large extent, medicalization consists of the biologization of phenomena labeled as illnesses. Whether it is used to mean the social control of individuals or even the threat to individual autonomy ${ }^{2}$, or to draw attention to the cover-up of the historical, social and political conditions which contribute to illness and suffering, healthcare professionals are generally considered as agents of this process.

\section{Medicalization and "self-medicalization"}

While it is accepted that medicalization is the result of a social construction in as much as it consists in defining a problem or a phenomenon using medical language, this social construction is not created solely by members of the medical profession, and the paternity of medicalization is not confined to healthcare professionals. Medicalization is no more the exclusive preserve of the medical profession than is the use of substances for medical purposes the exclusive result of prescriptions. It is sometimes practiced by individuals themselves, which is revelatory not only of a form of medicalization involving non-specialists (Lowenberg and Davis, 1994; Fassin, 1998) but also of medicalization by non-specialists. The decision to consult a doctor, and thus submit to medical judgment, is part of a medicalization process which may or may not be confirmed, prolonged or terminated, depending on the doctor's semiological interpretation of that person's state. In choosing to "pathologize" a behavioral trait or a physical manifestation through recourse to a medical consultation, subjects are thus already engaging in a form of medicalization of the phenomenon.

${ }^{2}$ Lock and Nguyen (2010) nevertheless qualify this statement by showing how medical practices can simultaneously act as modalities of social control and as a way of relieving pain or treating an illness, and that they are able to both subordinate and emancipate individuals. 
What is more, not only do subjects participate in medicalization from the moment they decide to turn to a medical authority, they become its instigator when, on their own initiative, they have recourse to medicines for problems or phenomena that a doctor would not necessarily have medicalized. In this case, the process of medicalization depends on the subjects themselves. This process is demonstrated in the following study carried out on reasons for and practices of self-medication in France today (Fainzang, 2012).

\section{The Study}

\section{Field methods}

The study was done partly in the Paris region and partly in the south of France (in the Languedoc-Roussillon and Pyrénées-Orientales regions). It was carried out among populations living in both urban and rural areas and belonging to different social milieus referred to as the "middle classes" which - however ambiguous the notion may be (Chauvel, 2006) - nowadays cover the intermediate classes and part of what used to be the working and upper classes. The surveys carried out in Paris and its suburbs included forty persons, primarily encountered using the so-called "snowball" method, with initial informants indicating other potential informants through the intermediary of their networks of acquaintances, who in turn mentioned people they knew, thus giving a relatively diverse population. The risk of the group of informants being too socially homogeneous was somewhat reduced by the diversity of the networks of acquaintances called upon. Some gave the names of family members, others mentioned friends, neighbors, work colleagues, members of associations, etc. who proved to be very different from the initial informants in terms of social and economic status or ideological profile. In progressively constituting a group of informants in this way, at the same time (and paradoxically) one moves away from the initial types of persons studied. Furthermore, in order to reduce this risk, I chose to vary the starting points within the networks, thus encouraging the creation of what might be considered a multitude of "snowballs", with each initial snowflake coming from a different source.

The surveys were carried out at the informants' homes and consisted primarily of interviews. These interviews were designed to gather information on the different problems for which they had treated themselves in the past, or were doing so at the time of the study; the conditions under which they chose either to consult a doctor or to treat themselves; the resources they used to identify the problem and to select the appropriate treatment; the strategies adopted to ensure a satisfactory risk/benefit ratio, etc. Where possible, these interviews were accompanied by an in situ observation, in accordance with anthropological methodology, of what the informants chose to do when faced with a physical or psychological phenomenon they felt to be problematic.

To compensate for the limits of interviews compared with the unequalled fruitfulness of direct observation, attempts were made to obtain access to informants' medicine cabinets, using a method tested during a previous study performed a decade ago on peoples' relationships to medicines (Fainzang, 2001) and their social uses (Fainzang, 2005). The principle was to determine the contents of the household pharmacy and to obtain all possible information on the way the medicines stored in it were acquired and the reasons for using them. With this method, it was possible to find out which medicines were taken following a prescription or as self-medication, and to see whether in turn self-medication was done subsequent to an earlier prescription or to another mode of acquiring them. Finally, these data were compared with those gathered during the previous study. 


\section{The regulatory context}

For the past few years, France has encouraged self-medication for what are essentially economic reasons. In a bid to reduce health costs borne by social security insurance, authorities largely encourage people to practice self-medication, and have put in place various public policies to promote this, with the view of leading consumers to finance more of their own drug expenses. In particular, public authorities have decided to stop reimbursing a large number of pharmaceutical specialties and published a decree (Decree $\mathrm{n}^{\circ}$ 2008-641, June 30, 2008) authorizing direct access to 217 drugs (this number has increased since then). These incentives were accompanied by recommendations for consumers aimed at managing the practice and defining its conditions, the main one being that it should be done only in "benign situations", as noted on the Internet site of the Ministry of Health ${ }^{3}$. This decision was taken after publication of a report on self-medication (Coulomb and Baumelou, 2007), prepared at the request of the Ministry of Health and submitted to the Minister in 2007. The report (called the "Coulomb Report"), which noted the weak development of self-medication in France compared to other European countries, suggested coordinating self-medication by enabling health professionals to "go along with" access to drugs in pharmacies, and by recommending that pharmacies retain the monopoly on the sale of drugs.

For public authorities, self-medication includes only those drugs for which a medical prescription is optional - that is, those the patient can buy with or without a prescription. It refers to the fact of treating oneself according to one's symptoms with drugs freely accessible and acquired from a pharmacist, without having been examined by a physician and thus without a prescription ${ }^{4}$. However, it should be pointed out that this is a normative or prescriptive rather than descriptive definition, and one the anthropologist cannot accept insofar as his/her role is to study the actual practices of the social actors.

\section{Defining Self-medication}

Literally speaking, self-medication is the use of medicines based on one's own decision. Lecomte (1999) considers that in a broader sense: "Self-medication consists of making a selfdiagnosis and treating oneself without receiving any medical advice". But, in a narrower sense, it is "the acquisition of a substance without a prescription that we call self-medication" (p. 49). Yet, numerous studies have shown that the choice of medicine at any given time may be based on a previous prescription. It is obvious that medicine can be procured through prescription but used in a context that is different from that for which it was prescribed, either for a different illness or at another moment in time - yet it remains self-medication. I will thus avoid adopting too narrow a vision of self-medication that does not take into account all the possible uncontrolled uses of prescriptions (buying medicines for future use, for someone else, etc.). Molina (1988) goes so far as to consider that when patients ask a doctor to prescribe a medicine they believe to be effective, it is in fact the patients who are prescribing products for themselves via the intermediary and with the approval of the doctor. Similarly, Van der Geest et al. (1996) believe that to some extent all medication is self-medication, insomuch as doctors do not usually administer the medicines themselves and cannot therefore be certain they are being taken as prescribed. I do not adopt such an extreme position, and

\footnotetext{
${ }^{3}$ http://www.sante.gouv.fr

4 http://ansm.sante.fr/Dossiers-thematiques/Medicaments-en-acces-direct/Medicaments-en-acces$\operatorname{direct} /($ offset $) / 0)$.
} 
prefer the view of Buclin and Hammon (2001), who state that it is patients' recourse to a medicine on their initiative which defines self-medication. More precisely, in this article, I consider self-medication to be the use of a medicine on one's own initiative, without consulting a doctor for the problem in question, whether the medicine is already in one's possession or whether one procures it to this end (in a pharmacy or from another person). In this study, I chose to restrict myself to biomedical medicines ${ }^{5}$.

\section{Self-medication and free will}

For some, self-medication is considered a way of asserting one's self-sufficiency in regards to one's health and one's independence in relation to physicians ${ }^{6}$. Moreover, that selfmedication is increasingly advocated in the name of autonomy and the moral and civic categories that accompany it, such as responsibility. Self-medication is closely related to the issue of autonomy because advocacy for self-medication, in certain cases, encourages doing away with the involvement of the prescribing physician.

The autonomy of persons practicing self-medication cannot of course be experienced in total independence of all outside influence. Their choices are in part built upon and conditioned by advice from those around them, by advertising, by Internet, etc. A person is never entirely independent and is subjected to a thousand different influences from the immediate social environment and from global society. As noted by R. Massé (2003), the recognition of free will in decision-making does not "mean conceiving of a theoretical citizen completely free of all exterior influence. Each one of us is influenced, or even constrained in a certain measure, by pressure from family members, by the values, norms, duties, and obligations bestowed upon us by society" (p. 219). But the latter appear beneath the surface, as it were, with the subject acting as a sounding-board for these different influences. Whether the consumer follows a former prescription or not, and whether he takes the advice of another person or not, in the case of self-medication, the emphasis is on the role of his choices and the exercise of his autonomy. The choice to self-medicate indicates a personal choice in the sense that, though resulting from these influences, it does not depend on medical prescriptions. As emphasized by Thoer et al. (2008): "the question of the subject's autonomy is at the center of the practice of using medicines without medical advice" (p. 37).

\section{From self-diagnosis to self-medication}

Self-medication presupposes a series of prior stages: self-examination, self-diagnosis and self-prescription. Self-examination may lead to a sign being translated into a symptom. Elsewhere (Fainzang, 2011) I have shown that, whereas in medical semiology symptoms are

\footnotetext{
${ }^{5}$ Unlike numerous anthropological works, which more often than not perceive self-medication as recourse to complementary or "indigenous" medicines, as opposed to recourse to biomedical technology (Lock and N'Guyen, 2010), my research relates exclusively to the use of industrial biomedical pharmaceuticals, even though this usage is sometimes found in practices borrowed from systems of heterodox thinking. Nor does the study address the use of homeopathy, since controversy surrounding the use of drugs and self-medication in France is centered on the consumption of synthetic drugs and the risks they carry.

${ }^{6}$ A study carried out jointly by the opinion poll institutes CSA ("Conseil, Sondage et Analyse") and CECOP ("Centre d'Etudes et de Connaissances sur l'Opinion Publique") thus showed that, for 55\% of persons interviewed, self-medication meant having "autonomous management of one's health" (CSA/Cecop, 2006).
} 
different from signs, authors use these terms in different ways, so that the way the terms are linked together to describe the process also varies. My use of the term "symptom" is closer to Young's (1976) in the sense that the sign, the thing perceived, here acquires the status of symptom from the moment it is considered to be pathological within the context of a social process. However, during a subject's self-examination and self-diagnosis, the sign (as a bodily sign) is converted into a symptom, whereas the symptom is in turn converted into a sign of a pathological state, leading to the need to medicalize the problem.

Yet, while it is generally attributed to medical expertise, the decoding of signs is not the exclusive preserve of healthcare professionals. The two registers (perceptive and cognitive) identified by Shands (1970) to characterize respectively the patient's activity as opposed to the doctor's activity are, in the case of self-medication, experimented with and employed by a single individual. The signs may therefore be both of a perceptive and cognitive nature and, for the subject, constitute bodily manifestations which must be understood, translated or interpreted. Of course, this act of self-medicalization is not strictly individual, in as much as this identification process is the product of multiple influences. Thus, subjects react in a variety of ways to a phenomenon, depending on several factors: their former experience with it, any past consultations with a doctor for a similar problem and whether the problem was resolved, whether or not they obtain additional information on the matter (from Internet and other media for example), the opinions of friends or family, advice from pharmacists, and whether they know someone who had experienced the same problem. Consequently, while we might agree with Sebeok (1994) that symptoms are "not arbitrary signs"7, their meaning is not necessarily "automatic" to the subjects.

The construction/identification of a symptom raises the fundamental question of the distinction between the normal and the pathological. For Canguilhem (1966), the judgment of what is pathological depends on who institutes the norm. Canguilhem places this judgment in the register of expertise or medical authority. Yet, in the case of self-medication, it is the subjects who establish their norms, norms that will be juxtaposed with - or possibly superimposed on - those established by biomedical discourse or by the pharmaceutical industry, or by their close friends and family, and therefore norms the social environment (close kin, friends, colleagues, media, etc.) plays a part in constructing.

\section{Examples from the study}

Mrs. V., employed in a printing firm in the Paris region, had difficulties falling asleep after her husband left her. She told her mother, who gave her a box of Stilnox ${ }^{\circledR}$, a hypnotic $\operatorname{drug}^{8}$, and suggested that she take one every evening, as she herself did to deal with her own insomnia. Relying on her mother's advice, she took the hypnotic medicine. Deeming that Stilnox ${ }^{\circledR}$ was not sufficiently effective, she later switched to Noctran ${ }^{\circledR}$ (which combines several active substances), ${ }^{9}$ which was recommended to her by a colleague.

Besides consulting friends and family, when confronted with a symptom they do not know, people also look for advice on the Internet. For instance, they can consult discussion forums

\footnotetext{
7 According to Sebeok (1994), from a doctor's perspective, to a given symptom corresponds necessarily a meaning and consequently a specific disease. He writes in this regard: "a symptom is a compulsive, automatic, non-arbitrary sign, such that the signifier is coupled with the signified in the manner of a natural link" (p. 46).

${ }^{8}$ The International Nonproprietary Name is zolpidem.

${ }^{9}$ Dipotassic clorazepate, Acepromazine, Aceprometazine.
} 
to help them identify a symptom, its etiology or its level of seriousness. This was the case for Mrs. F., a psychologist in Paris, who felt a very nasty, bitter taste in her mouth as soon as she ate or drank something. She wondered if this sensation was pathological, and whether there was any cause for concern. She asked a pharmacist what the problem might be, but he replied that he did not know and that there was nothing to worry about. The sensation was so unpleasant that she decided to take antihistaminic medicine to try to control what she thought to be an allergy. As the bitter taste persisted, she then visited an Internet forum. She discovered that many other people had already experienced the same unpleasant sensation, and upon reading several comments, she learned that this was due to the consumption of certain kinds of pine nuts imported from China - the exact same ones she had eaten the day before - and that the sensation would disappear after one week. Mrs. F. had thus gained knowledge about this "symptom" which not only reassured her, but also taught her how to prevent it from happening again and without having to take a course of medicine.

This operation is twofold, since the person must first identify what he/she thinks to be pathological, then consider whether this sign/symptom is a case for which self-medication is indicated. To examine at what point a bodily sign becomes a symptom (or a pathological state) requiring medicalization, is, in the context of self-medication, to simultaneously examine the criteria that cause the sign to shift from the status of normal to that of pathological, as well as the criteria which cause the symptom to shift from the status of a sign to be dealt with (that is to say to be medicalized) to that of a sign to be dealt with by oneself (i.e. to be what I call 'self-medicalized'). So, for the person concerned, it is not so much a question of relying on a medical norm to define the pathological as a question of appraising the sign or the phenomenon in relation to what the subject considers to be the norm for his/her body. For instance, the subject may recognize a phenomenon as something he/she has already seen or perceived (in or on his/her body or the body of someone else, such as a close relative - especially one's child), the appearance of which may have been followed or preceded by another symptom in a sequence which takes on a meaning. But it may also be the first time a given sign is perceived, to which the subject attempts to give a meaning. For example, Germaine, a retired teacher, had a husky voice. She thought that it was a sign of aging, and considered it to be normal. She was, however, somewhat bothered by her voice, finding it to be unpleasant, so she bought sweets that she could suck on to soothe it. In spite of this, her voice remained husky, and one day she realized that people didn't recognize her any longer on the phone, which she didn't think was normal; her change in voice then became pathological in her eyes. It is thus the qualification of pathological that makes this bodily sign a symptom to be medicalized.

When subjects feel pain or discover another physical sign, the meaning they assign to it can lead to different self-medication practices. Pain, for example, first entails an interpretation before giving rise to the pharmaceutical response that self-medication implies. Subjects try to interpret their pain by relating it to what they feel and what they have felt before, the information they have on their problem, what symptoms they have previously identified, their perception of the ways in which healthcare professionals have managed their problem in the past, etc. This information will guide the way in which they choose to eliminate or alleviate it. So not only does medicalization of this sign depend on the context in which patients find themselves and on their past history, but also, in the context of self-medication, this translation activates a system of norms that may be unique to the individual, leading him or her to choose to take a medicine, following their own analysis of the context in which the symptom appeared. For example, Mrs. D. might interpret a stomach ache as a pain caused by her impending period because she was in a pre-menstrual phase, whereas Mr. G. might 
interpret a stomach ache as an intestinal disorder because he had just returned from a trip abroad, while Miss. F. would put it down to gastric pain following a heavy meal she had just eaten at a restaurant. Or, subjects may relate it to their nervousness, in the event they are going to participate in a social action that generates fear or emotion, such as public speaking or performance, a medical check-up, a romantic encounter, an examination, etc. The same person may also attribute different meanings to the same sign, depending on when he/she has the experience. This attribution will of course affect the response made. Depending on the case, the subject may take anti-spasmodics, analgesics, anti-inflammatories, intestinal antiseptics or tranquillizers. Then, beyond the specific sensorial dimension of the symptom, when the medicine taken proves ineffective, the subject may be led to change his/her interpretation of the pain when the latter persists, even though it should have ceased, or if it reappears (for instance, when a woman is no longer having her period, or when the social action involving emotion has been concluded). Management of this phenomenon is partly influenced by the way in which subjects have seen their doctor manage it. In this case, we are confronted with a model replicating the medicalization that was previously practiced by the medical profession.

The succession of phases may, however, work in reverse and cause subjects to demedicalize a phenomenon that has previously been medicalized by the medical profession. For instance, Mrs. C., a speech therapist in Paris, had a sore throat following several previous episodes of pharyngitis. Each time, she was prescribed antibiotics, but she felt that the treatment had simply weakened both her and her intestines without solving the problem. When the sore throat came back, she once again consulted the doctor, but when he once more prescribed antibiotics, she chose not to take them. While her rejection of the antibiotic treatment was in part due to her conviction that it was ineffective because the problem regularly recurred ${ }^{10}$, it was also encouraged by her realization of the new context in which the sore throat had appeared - namely, the break-up of a romantic relationship -leading to her conclusion that her sore throat was the result of somatization. Following a friend's advice, she took homeopathic lozenges, but without satisfying results. As her sore throat persisted, she talked to one of her colleagues who told her that a sore throat may be caused by intolerance to sugar. Mrs. C. then decided "to do an experiment." She bought and ate a "big piece of chocolate" and straightaway felt an acute sore throat. She concluded that sugar maintained her repeated bouts of throat pains and decided to stop consuming it. "Sugar is the sweetness of life," she explained. "It is difficult to accept having to deprive oneself of it, but I've managed!" She associated the fact of accepting to deprive herself of this sweetness with the necessity of accepting the failure of her love affair. Her decision to cease all medication (both antibiotic and homeopathic) in order to cure her sore throat cannot be interpreted simply in terms of non-compliance. This is a case of demedicalization following what was previously self-medication (with homeopathic medicines), which in turn had followed the medicalization carried out by the doctor.

\section{Self-medication and "self-medicalization"}

\section{Disagreeing with the doctor}

${ }^{10}$ On doubts that patients might harbor with regard to the effectiveness of a treatment, see, in particular, Whyte, et al. (2002) 
Apart from reproducing medicalization initially provided by a doctor, self-medication can also result from a personal decision to medically interpret a phenomenon or a sensation not recognized as such by a doctor. Certain problems are medicalized and managed through selfmedication when the doctors consulted do not agree with the patient in qualifying a physical manifestation as a symptom or in recognizing the pathological nature of a symptom. This is the case in what doctors consider to be "functional disorders," symptoms not recognized as organic or physio-pathological (Cathebras, 2000). These are sometimes called 'medically unexplained symptoms' (Risor, 2010), an expression that patients often interpret as a diplomatic way of telling them there is nothing wrong with them. Sometimes, the subject will have developed personal knowledge about a specific ailment he/she has experienced. Mrs. A. decided to cure her headache by herself because it was not taken seriously by her doctor. She had what she called "the 48-hour ailment," a very intense headache which appears three times a year and lasts 48 hours, which she associated with stress at work. Her doctor was skeptical and became ironic when she talked to him about it, responding in a mocking tone that this disease didn't exist and that "it was all in her mind." Yet, she considered her headache to be a real pathological entity that always had the same manifestation, intensity and duration, and she associated it with her being overworked. Therefore, she decided that she should cure herself: "I know myself. In my case, it means that I am overloaded with work; I know what I need", she said. When her headache occurs, she takes high doses of anti-inflammatory pharmaceuticals around the clock. At the same time, she criticized working conditions for today's employees, who are submitted to greater and greater pressures in the present socioeconomic context that puts the pursuit of profits before the health of the individual.

Similarly, self-medication may occur when the doctor does not agree with an individual's interpretation of a phenomenon. In such cases, it is the subject's personal interpretation of a sign or phenomenon that may encourage him/her to medicalize it and to self-medicate. This was the case with Edith, a musician, who was treated for breast cancer (and who has since died of a brain tumor). She lived in a village in the south of France, near which a very highvoltage electrical power line had been installed. Being concerned about this proximity and fearing a new cancer, she decided to join an ecology movement as an activist. During the same period, she had headaches and problems sleeping. Edith was worried about contracting cancer through her exposure to the electromagnetic field, and did not trust the reassuring information supplied by public authorities and their expert reports on the absence of any danger from high-voltage lines. She talked to her doctor about her sleep problems and her headaches, which she believed to be due to the close proximity of the line. The response was that her unjustified anxiety was the sole cause of these manifestations, and they were not worth treating. She did not believe that her problems would go away of their own accord, so she decided on her own initiative to take anti-inflammatory medicines and anxiolytics to cope with her headaches and insomnia. As can be seen here, self-medicalization assigns meaning to an individual's pain or symptom.

In the same vein, it was Jean-Pierre's interpretation of his symptom, differing from that of his doctor, that led him to medicalize and treat himself. He was constantly sneezing and had a permanently runny nose, which he put down to allergies. But, his doctor concluded there was no allergy and suggested he keep out of draughts. Jean-Pierre was nevertheless convinced his problem was due to industrial and urban pollution, because his attacks ceased when he went away on holiday to the seaside. He therefore made the personal decision to take antihistamine medication, while criticizing not only the state of large cities, in particular the proximity of factories and industrial activity, but also urban policies and insufficient political will to regulate and limit automobile traffic - to which he attributed respiratory ailments he said 
many inhabitants suffered from. Here, medicalization was performed by the patient, as in cases observed by Raffaetà (2011) ${ }^{11}$ of people claiming to be suffering from allergies despite medical opinion to the contrary.

\section{Doing without a doctor}

The desire to medicalize one's own troublesome phenomenon can be observed in various situations where the doctor may not even have been consulted. For example, a mother may attempt to control her child's "excitability" when it is time to go to bed by administering codeine for its sedative properties. We can find a similar mechanism at work by Mr. R., an IT service engineer, who chose to take an anxiolytic (Lexomil ${ }^{12}{ }^{12}$ ) in an attempt to treat what he referred to as his "sweaty hands problem." a sensation from which he frequently suffered and which he found embarrassing. Consequently, self-medication can result from the choice to medically treat a phenomenon the doctor does not believe needs to be medicalized, or to which the subject attributes an etiology of which the doctor does not approve, or for which he/she has not even sought medical advice.

When individuals decide to medicalize a given physical manifestation, such as choosing to take Viagra ${ }^{\circledR}$ to treat erectile dysfunction, for example, the idea does not, of course, come solely from the individuals; it results from their belief in the discourse of the pharmaceutical industry that promotes such recourse. From this point of view, individuals are merely actors of such medicalization, as are indeed doctors who also simply promote the medical discourse with which their training and profession have made them so familiar (Good, 1998). But, individuals are nevertheless the authors of this process, the condition sine qua non for the decision to self-medicate. The individual decision to take psychotropic substances to treat insomnia or sildenafil to help with erectile dysfunction is self-medicalization even before becoming self-medication. Self-medication is the acting out of self-medicalization.

\section{Self-medicalization as commitment to a cause}

This process of self-medicalization may have social and/or political significance, judging from some of the cases presented here. Indeed, the views expressed by Marie, Edith and JeanPierre echo debates taking place in the public sphere, challenging a particular model of the actions and political or economic choices of French society. It is interesting to note the extent to which the phenomena they blamed for their problems are sensitive subjects in the French public arena.

"Work-related" stress and the pathogenic nature of the working environment are frequently called into question in the social sphere. Indeed, the exacerbated form of this stress is increasingly put forward as an explanation for such "suffering at work" (Dejours, 2008), or even of suicides in the workplace (Dejours, 2009), the occurrence of which go hand in hand with the determination expressed by families of the deceased to have the deaths recognized as "work accidents."

High-voltage power lines are also a subject of very lively debate and controversy in France. This has led various associations to protest against these lines and to confront EDF (Electricité de France) and its installations. The forms of protest to which these lines have given rise are passed on by numerous web sites, such as Antigauss, the national association

\footnotetext{
${ }^{11}$ In these cases where individuals demand patient status that is refused by their doctors, Raffaetà considers that there is "bottom-up medicalization" in as much as it involves doctors and patients.

${ }^{12}$ Bromazepam.
} 
against electromagnetic harm ${ }^{13}$. The debates include, on the one hand, those who cite problems considered to be caused by electromagnetic waves and the effects on health of highvoltage and very high-voltage lines (increased risk of infantile leukemia, changes in reproductive functions, sleep problems, stress and anxiety) ${ }^{14}$, and who demand application of the "principle of precaution"15. On the other, there are those who accept WHO's conclusions 16 that research has provided no data with which to establish any relationship of cause and effect between exposure to electromagnetic fields and the symptoms reported by users.

Allergies are also the subject of political debate. While the seasonal nature of certain allergies is easily recognized by all and therefore not a matter for controversy, there is no consensus on links between certain allergies and industrial pollution. This lack of agreement on the issue in the public sphere is partly due to the political nature of the alleged causes, which are the basis for demands made by environmentalists. As a consequence, when JeanPierre blamed pollution for what he assumed to be an allergy and took antihistamines to treat his symptoms, or when Edith took anxiolytics and anti-inflammatory medicines to treat her insomnia and headaches, which she blamed on the electromagnetic field created by the nearby very high-voltage power line, or when Marie blamed her work load for her headaches and took anti-inflammatory medicine to relieve the pain she believed to be caused by "workrelated stress", the medicalization they resorted to was accompanied by a discourse of accusation aimed at the social, economic and political situation. Here, self-medicalization takes the form of a protest against the fact that people's living and working environments have been taken over by commercial or industrial interests, by the pace and burden of work in the corporate world or by societal choices. Self-medicalization thus equates to a condemnation of a particular social, economic or political environment, and the medicalized sign becomes proof of the pathogenic nature of this environment.

\section{Conclusion}

When individuals become the authors of this process, choosing on their own to give a medical interpretation to a bodily phenomenon and a fortiori when they do not replicate a previous prescription for an identical problem, they are engaging in an autonomous form of medicalization. I therefore suggest the term "self-medicalization" to describe the tendency to make a decision on one's own to transform a given situation into a problem requiring medical treatment, and to choose the strategy required to deal with it (including self-information, selfgovernance, self-examination, self-prescription and self-medication). Self-medicalization consists of introducing a situation into the medical domain that, from a medical perspective, may not necessarily belong there, and in pathologizing a behavioral trait or bodily

${ }^{13} \mathrm{http} / / / \mathrm{www} \cdot$ aci-multimedia.net/bio/haute_tension.htm

14 Cf. "Lignes à haute tension: la prudence doit primer" (http://www.viepublique.fr/actualite/alaune/lignes-haute-tension-prudence-doit-primer.html).

15 The principle of precaution was first formulated in the context of the defense of the environment. It was contained in the 1992 Rio Declaration emanating from the United Nations Conference on the environment and development. It states that the absence of certainty, in a given state of scientific knowledge, should not delay the adoption of measures aimed at preventing risks of serious harm to the environment. Following several health crises, this was later enlarged to include the area of public health. According to this principle, all measures must be taken in situations of uncertainty to prevent a given risk in the area of health.

${ }^{16} \mathrm{http} / / / \mathrm{www}$. notre-planete.info/ecologie/energie/lignes_haute_tension_sante.php 
manifestation, possibly without or against medical advice. Self-medicalization is therefore consubstantial with self-medication, and the latter is the acting out of the former.

The link established in the social sciences between medicalization and social control aims at emphasizing the "individualization" of social problems, since medicalization is presumed to turn a social problem into an individual one. On the contrary, self-medicalization (that is, medicalization carried out by individuals themselves, possibly in opposition to or disagreement with medical discourse) may consist of the socialization, or even the politicization, of an individual problem. Through the diagnosis they give and the etiology they propose, individuals thus create a social problem from a personal one ${ }^{17}$. The choice of a medicinal solution to a condition perceived as a problem or disorder thus serves to validate the etiology recognized by the subject and becomes an act with a social impact. Selfmedicalization may thus be equivalent to asserting an economic, social or political cause behind people's health problems. Whereas the political significance of the concept of 'medicalization' is to draw attention to a process consisting in considering phenomena as medical when they are not necessarily medical, the political significance of 'selfmedicalization' is to underline the involvement of structural conditions (social, economic, political) in the pathologizing of bodily phenomena. In this case, self-medicalization is not always a question of the internalization of medical and therapeutic perspectives (Furedi, 2006) leading to a decision to make one's body dependent on drugs, but may also be the affirmation of a personal judgment - although still socially constructed - concerning the social causes of one's illness, and therefore the accomplishment of a political act.

\section{REFERENCES}

Ackerknecht E.H., 1946, Natural Diseases and Rational Treatment in Primitive Medicine, Bulletin of the History of Medicine 19: 467-497.

Aïach P. and D. Delanoë, eds, 1998, L'ère de la médicalisation, Economica: 15-36.

Brown P., 1987, Popular Epidemiology: Community Response to Toxic Waste-Induced Disease in Woburn, Massachusetts, Science, Technology \& Human Values 12, 3-4, 78-85.

Buclin T. and C. Ammon, eds, 2001, L'automédication : pratique banale, motifs complexes, Genève : Médecine et Hygiène.

Calvez M., 2009, Les signalements profanes de clusters : épidémiologie populaire et expertise en santé environnementale, Sciences sociales et santé 27, 2, 79-106.

Canguilhem G., 1966, Le normal et le pathologique, Paris, PUF.

Cathebras P., 2000, Douleur, somatisation et culture : peut-on aller au-delà des stéréotypes ?, Douleur et analgésie 13, $3: 159-162$.

Chauvel L., 2006, Les classes moyennes à la dérive, Paris: Seuil, coll. La république des idées.

\footnotetext{
${ }^{17}$ Although self-medicalization may amount to the politicization of the phenomenon in question, the presumed relationship between harm and cause does not necessarily fall within the framework of collective discourse - unlike discourse on popular epidemiology (Brown, 1987; Calvez, 2009) - and does not necessarily involve any claim to expertise, even if subjects sometimes attempt to validate their diagnoses and therapeutic processes with a healthcare professional.
} 
Clarke A., 2000, Technosciences et nouvelle biomédicalisation: racines occidentales, rhizomes mondiaux, Sciences sociales et santé 18, 2: 11-42.

Clarke A.E., L. Mamo, J.R. Fishman, J.K. Shim, J.R. Fosket, 2003, Biomedicalization: Technoscientific Transformations of Health, Illness and US Biomedicine, American Sociological Review 68, 2: 161-194.

Cohen D., Bouchard L., 1995, Médicalisation et contrôle social, Actes du colloque, groupe de recherche sur les aspects sociaux de la santé et de la prévention, ACFAS (Coll. Les cahiers scientifiques, 84).

Conrad P., 1975, The discovery of hyperkinesis: notes on the medicalization of deviant behavior, Social Problems 23, 1: 12-21.

Conrad P., 1992, Medicalization and social control, Annual Review of sociology 18: 209-232.

Conrad P., 2007, The medicalization of Society. On the transformation of Human Conditions into Treatable Disorders. Baltimore: The Johns Hopkins University Press.

Conrad P., J.W. Schneider, 1985, Deviance and Medicalization. From Badness to Sickness, Columbus: Merrill Publishing $\mathrm{C}^{\circ}$.

Coulomb A., Baumelou A., 2007, Situation de l'automédication en France et perspectives d'évolution : marché, comportements, positions des acteurs, Rapport établi à la demande du ministère de la santé et de la protection sociale, 32 pages.

Dejours C., 2008, Travail, usure mentale : Essai de psychopathologie du travail, Paris: Bayard, Coll. Essais.

Dejours C., 2009, Suicide et travail : que faire ?, Paris : PUF.

Desclaux A. and J.J. Lévy, 2003, Cultures et médicaments. Ancien objet ou nouveau courant en anthropologie médicale ?, Anthropologie et Sociétés 27, 2, 5-21.

Dumit J. and N. Greenslit, 2006, Informated health and Ethical Identity Management, Culture, Medicine and Psychiatry 30, 2: 127-134 (special issue: "Pharmaceutical Cultures")

Fainzang S., 2001, Médicaments et société. Le patient, le médecin et l'ordonnance, Paris : Presses Universitaires de France.

Fainzang S., 2005, Religious Attitudes toward Prescriptions, Medicines and Doctors in France. Culture, Medicine and Psychiatry 29, 4: 457-476.

Fainzang S., 2011, From self-diagnosis to self-medication: constructing and identifying symptoms, in Fainzang S. and C. Haxaire, eds, Of Bodies and symptoms. Anthropological perspectives on their social and medical treatment, Tarragona: URV Publicacions: 39-58.

Fainzang S., 2012, L'automédication ou les mirages de l'autonomie, Paris: Presses Universitaires de France.

Fassin D., 1998, Avant-propos : les politiques de la médicalisation, in : Aïach P. and D. Delanoë, eds, L'ère de la médicalisation, Paris, Anthropos/Economica : 1-13.

Foucault J-P., 1965, Naissance de la clinique, Paris : Presses Universitaires de France.

Furedi F., 2006, The end of professional dominance, Society 43, 6: 14-18.

Good B.J., 1998, Comment faire de l'anthropologie médicale? Médecine, rationalité et vécu. Le Plessis-Robinson, Institut Synthélabo pour le progrès de la connaissance.

Gori R., M.-J. Del Volgo, 2005, La Santé totalitaire : Essai sur la médicalisation de l'existence, Paris : Denoël.

Hallowell A. I., 1941, The Social Function of Anxiety in a Primitive Society, American Sociological Review 6: 869-881 (republished in Culture, Disease and Healing, D. Landy, ed., New York, Macmillan, 1977). 
Illich I., 1975, Némésis médicale. L'expropriation de la santé. Paris: Seuil.

Lecomte T., 1999, Chiffres de l'automédication en France et à l'étranger : 49-56, in Queneau P., ed., Automédication, autoprescription, autoconsommation, Paris : John Libbey.

Lock M. and V.K. Nguyen, 2010, An anthropology of biomedicine. Malden/Oxford: WileyBlackwell.

Lowenberg J.S. and Davis F., 1994, Beyond medicalisation-demedicalisation: the case of holistic health, Sociology of health \& Illness 16, 5, 579-599.

Lupton D., 1997, Foucault and the medicalisation critique, in: Foucault, Health and Medicine, Petersen A. and Bunton R., eds, London: Routledge: 94- 110.

Molina N., 1988, L'auto-médication, Paris: Presses universitaires de France (Coll: Les champs de la santé).

Nichter M., 1989, Pharmaceuticals, the Commodification of health, and the healthcaremedicine use transition, in Nichter M., M. Nichter, Anthropology and international health. Asian case studies, Dordrecht: Kluwer Academic Press: 265-326.

Raffaetà R. 2011, The allergy epidemic, or when medicalisation is bottom-up, in Fainzang S. and C. Haxaire, eds, Of Bodies and symptoms. Anthropological perspectives on their social and medical treatment, Tarragona: URV Publicacions, pp. 59-77.

Risor M. Bech, 2010, Healing and recovery as a social process among patients with medically unexplained symptoms (MUS), in Fainzang S., H.E. Hem and M. B. Risor, eds, The Taste for Knowledge. Medical Anthropology facing Medical Realities, Aarhus: Aarhus University Press, pp. 133-149.

Sebeok T.A., 1994, Signs. An introduction to Semiotics. Toronto/Buffalo/London: University of Toronto Press.

Shands H.C., 1970, Semiotic Approaches to Psychiatry, The Hague: Mouton.

Van der Geest S., S.R. Whyte and A. Hardon, 1996, The Anthropology of Pharmaceuticals: a biographical approach, Annual Review of Anthropology 25: 153-178.

Whyte S. R., S. Van der Geest, A. Hardon, 2002, Social lives of medicines, Cambridge, Cambridge University Press (coll. Studies in medical anthropology).

Young A., 1976, Some Implications of Medical Beliefs and Practices for Social Anthropology", American Anthropologist 78: 5-24.

Zola I.K., 1972, Medicine as an institution of social control, Sociological Review 20, 487-504. 